\section{Multiple recycled aggregate properties analysed by X-ray microtomography}

C. Thomas $^{\mathrm{a}, *}$

carlos.thomas@unican.es

J. de Brito ${ }^{b}$

V. Gil

J.A. Sainz-Aja

A. Cimentada

aLADICIM (Laboratory of Materials Science and Engineering), University of Cantabria, E.T.S. de Ingenieros de Caminos, Canales y Puertos, Av./Los Castros 44, 39005 Santander, Spain

CERIS-ICIST, Instituto Superior Técnico, Universidade de Lisboa, Av. Rovisco Pais, 1049-001 Lisbon, Portugal

*Corresponding author.

Abstract

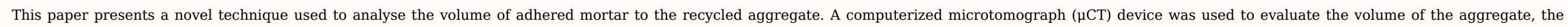

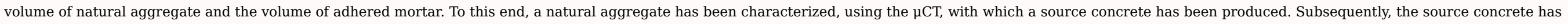

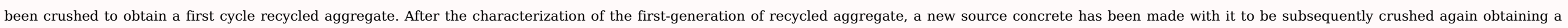

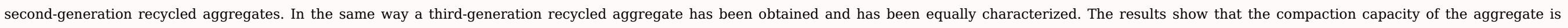

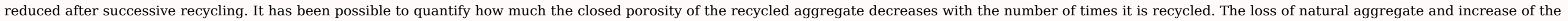
volume of adhered mortar have also been evaluated using this technique.

Keywords: Waste; Recycled aggregate; Recycled aggregate concrete; Multiple recycling; Adhered mortar; $\mu$ CT analysis

\section{Introduction}

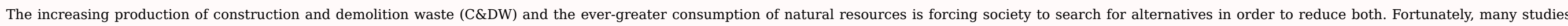

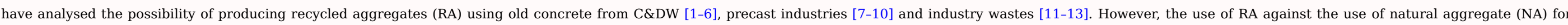

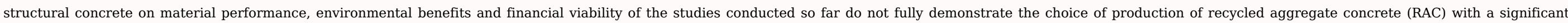
advantage [14].

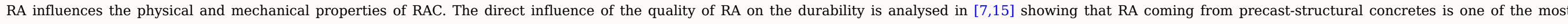

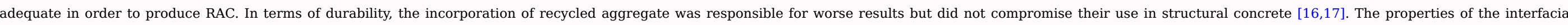

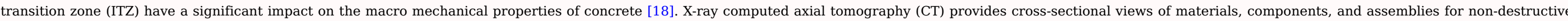

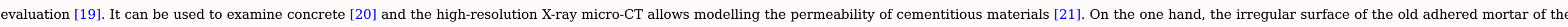

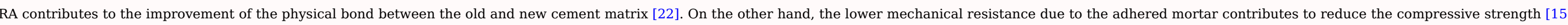

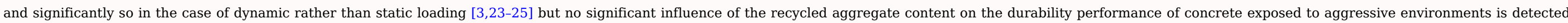
after years [26]. 


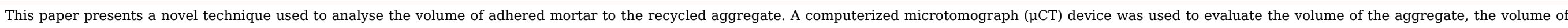

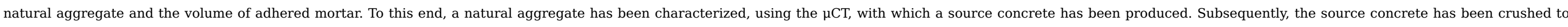

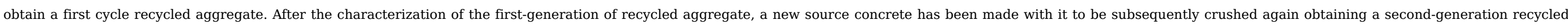

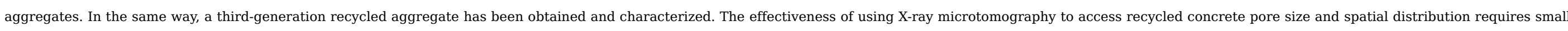
samples in order to increase the resolution, which is still a drawback to overcome [22]. In the present case, representative samples of the recycled aggregates have been obtained and analysed.

\section{Experimental program}

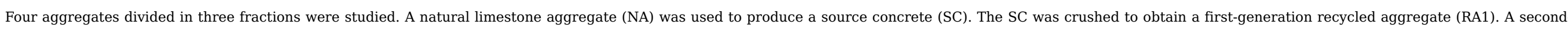

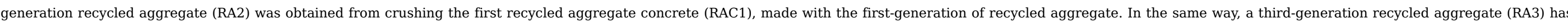

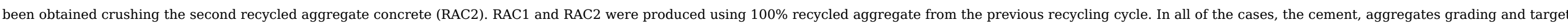

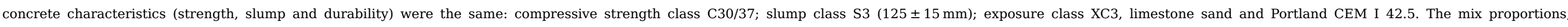

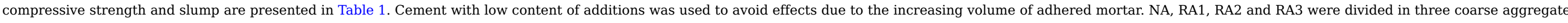

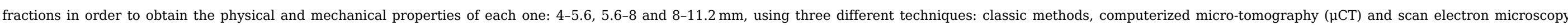
(SEM).

Table 1 Mix proportions (by $\mathrm{m}^{3}$ ) and main properties of concrete.

\begin{tabular}{|c|c|c|c|}
\hline Concrete & $\mathrm{SC}$ & RAC1 & RAC2 \\
\hline Sand $(0-2)(\mathrm{kg})$ & 732 & 732 & 732 \\
\hline Coarse aggregate (4-8) (kg) & 205 & 183 & 171 \\
\hline Coarse aggregate (8-16) (kg) & 443 & 396 & 371 \\
\hline Coarse aggregate (16-22) (kg) & 327 & 292 & 274 \\
\hline Cement (CEM I 42.5) (kg) & 350 & 350 & 350 \\
\hline Water (kg) & 194 & 194 & 194 \\
\hline Extra water (kg) & 0 & 40 & 49 \\
\hline Effective w/c ratio & 0.55 & 0.55 & 0.55 \\
\hline Apparent w/c ratio: & 0.55 & 0.67 & 0.69 \\
\hline Slump (cm) & 12.4 & 12.6 & 12.1 \\
\hline Compressive strength (MPa) & 55.9 & 54.1 & 53.3 \\
\hline
\end{tabular}

\subsection{Properties of the aggregate by classic methods}

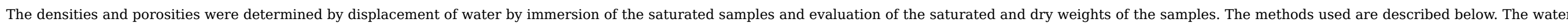

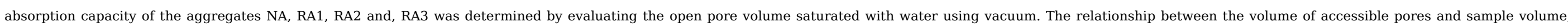
obtained by evaluating the difference between saturated and dry weights, provides the porosity of the material.

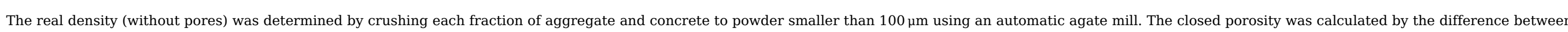
the relative volume and the real volume. The open porosity was calculated by the difference between the apparent volume and the relative volume. 


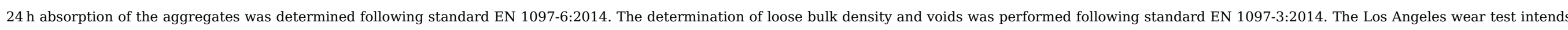

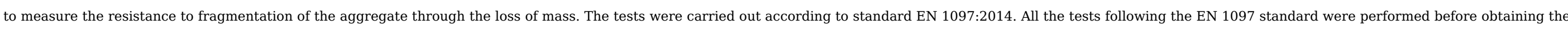
final mix proportions (Faury). For this reason, the commercial natural aggregate and the aggregate resulting from crushing the SC and RC, not the 4-5.6, 5.6-8 and 8-11.2 mm fractions, were considered.

\subsection{Computerized micro tomography}

In order to analyse the properties of the samples, a computerized micro-tomograph was used. The equipment can provide qualitative and quantitative information of the tested specimens

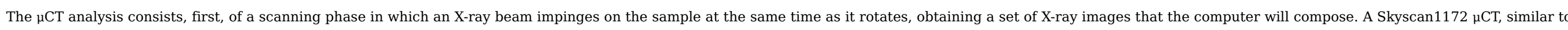

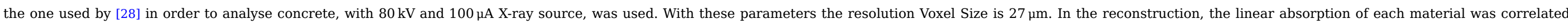
with a shade of grey between 0 [black] and 255 [white] using the same parameters for all the specimens.

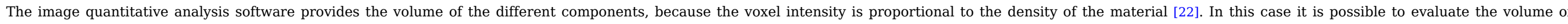

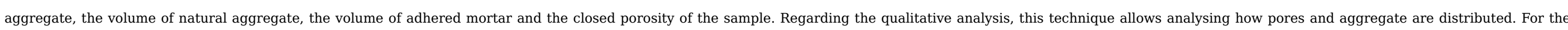
identification of the aggregate and cement paste phases, previous analyses were made using only, on the one hand, cement paste and, on the other hand, natural aggregate used in the research.

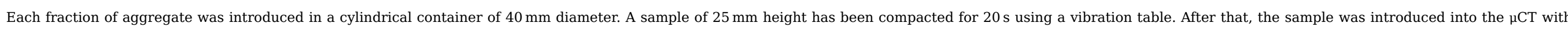
the container. Each analysis, with the indicated parameters lasts approximately $10 \mathrm{~h}$.

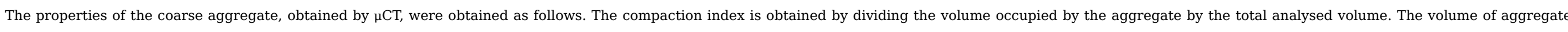

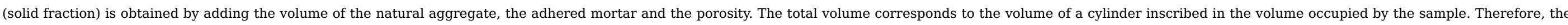

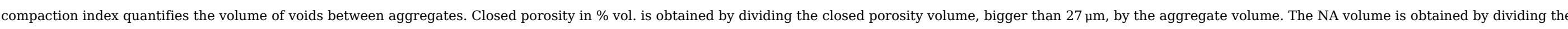

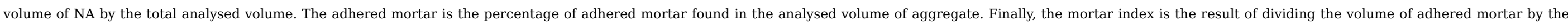
volume of natural aggregate.

\subsection{Scan electron microscopy}

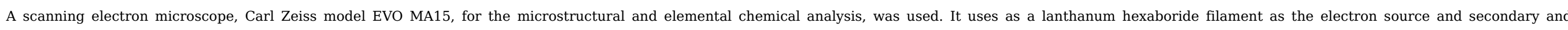
backscattered electrons detectors and an Oxford Instruments X-ray detector. This SEM can work in low vacuum allowing the observation of samples without conductors nor need of metallization.

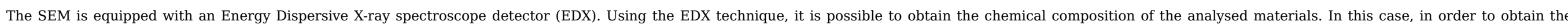
chemical composition by weight and atomic percentage, a sample of each aggregate was crushed to $100 \mu \mathrm{m}$ powder and analysed by EDX.

\section{Results and discussion}

In this section, the obtained results are shown and analysed.

\subsection{Physical and mechanical properties by classic methods}

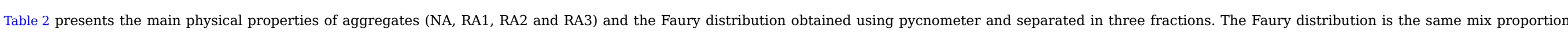

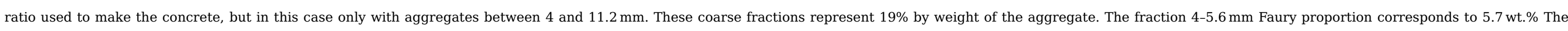
fraction $5.6-8 \mathrm{~mm}$ represents $6.3 \mathrm{wt} . \%$. and the fraction $8-11.2 \mathrm{~mm} 6.8 \mathrm{wt} . \%$.

Table 2 Physical properties of the coarse aggregate obtained by classic methods.

\begin{tabular}{|c|c|c|c|c|}
\hline Aggregate & Fraction $[\mathrm{mm}]$ & Relative density $\left[\mathrm{g} / \mathrm{cm}^{3}\right]$ & Real density $\left[\mathrm{g} / \mathrm{cm}^{3}\right]$ & Closed porosity [\% vol.] \\
\hline NA & Faury & 2.630 & 2.744 & 0.099 \\
\hline
\end{tabular}




\begin{tabular}{|c|c|c|c|c|}
\hline & $4-5.6$ & 2.677 & 2.832 & 0.134 \\
\hline & $5.6-8$ & 2.657 & 2.701 & 0.038 \\
\hline & $8-11.2$ & 2.639 & 2.786 & 0.127 \\
\hline \multirow[t]{4}{*}{ RA1 } & Faury & 2.505 & 2.662 & 0.895 \\
\hline & $4-5.6$ & 2.562 & 2.695 & 0.759 \\
\hline & $5.6-8$ & 2.539 & 2.707 & 0.958 \\
\hline & $8-11.2$ & 2.496 & 2.668 & 0.981 \\
\hline \multirow[t]{4}{*}{ RA2 } & Faury & 2.463 & 2.558 & 0.542 \\
\hline & $4-5.6$ & 2.505 & 2.606 & 0.576 \\
\hline & $5.6-8$ & 2.489 & 2.591 & 0.582 \\
\hline & $8-11.2$ & 2.474 & 2.558 & 0.479 \\
\hline \multirow[t]{4}{*}{ RA3 } & Faury & 2.418 & 2.505 & 0.496 \\
\hline & $4-5.6$ & 2.489 & 2.604 & 0.656 \\
\hline & $5.6-8$ & 2.455 & 2.506 & 0.291 \\
\hline & $8-11.2$ & 2.392 & 2.492 & 0.570 \\
\hline
\end{tabular}

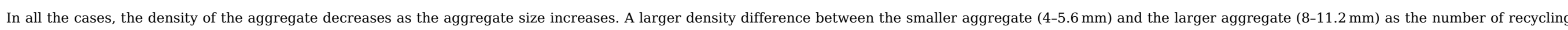

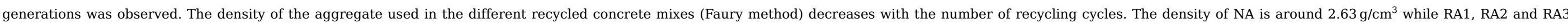
present a density $4 \%, 6 \%$ and $8 \%$ lower, respectively.

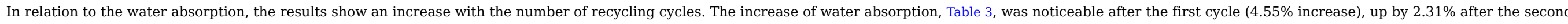

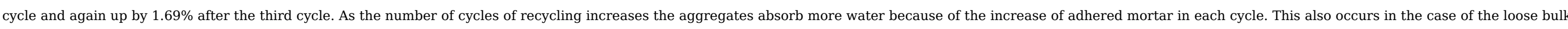
density, voids volume and Los Angeles coefficient.

Table 3 Physical and mechanical properties of the coarse aggregate obtained by classic methods.

\begin{tabular}{|c|c|c|c|c|}
\hline Aggregate & $\mathrm{W}_{24}[\% w t]$. & Loose bulk density $\left[\mathrm{kg} / \mathrm{m}^{3}\right]$ & Voids [\%vol.] & Los Angeles [\%wt.] \\
\hline NA & 1.09 & 1355.1 & 47.6 & 27.93 \\
\hline RA1 & 5.64 & 1132.2 & 55.2 & 38.81 \\
\hline RA2 & 7.95 & 1034.4 & 59.3 & 41.18 \\
\hline RA3 & 9.64 & 990.1 & 62.7 & 40.89 \\
\hline
\end{tabular}

\subsection{Computerized micro tomography}

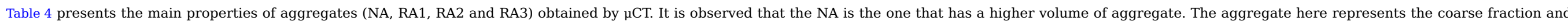




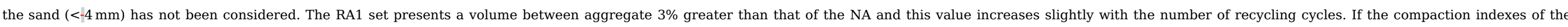
various fractions are compared, the 4-5.6 mm fraction occupying higher volume is noticed and this value decreases with the number of recycling cycles.

Table 4 Properties of the coarse aggregate obtained by $\mu \mathrm{CT}$.

\begin{tabular}{|c|c|c|c|c|c|c|}
\hline Aggregate & Fraction $[\mathrm{mm}]$ & Compaction index [\% vol.] & Closed porosity [\% vol.] & NA volume [\% vol.] & Adhered mortar [\% vol.] & Mortar index [\% vol.] \\
\hline \multirow[t]{4}{*}{ NA } & Faury & 60.350 & 0.044 & 60.350 & 0.000 & 0.000 \\
\hline & $4-5.6$ & 60.877 & 0.030 & 60.877 & 0.000 & 0.000 \\
\hline & $5.6-8$ & 61.015 & 0.026 & 61.015 & 0.000 & 0.000 \\
\hline & $8-11.2$ & 60.978 & 0.073 & 60.978 & 0.000 & 0.000 \\
\hline \multirow[t]{4}{*}{ RA1 } & Faury & 57.605 & 0.713 & 25.355 & 55.489 & 1.268 \\
\hline & $4-5.6$ & 59.794 & 0.978 & 27.910 & 53.322 & 1.142 \\
\hline & $5.6-8$ & 59.413 & 0.667 & 26.318 & 55.704 & 1.258 \\
\hline & $8-11.2$ & 55.724 & 0.554 & 23.048 & 58.639 & 1.418 \\
\hline \multirow[t]{4}{*}{ RA2 } & Faury & 57.051 & 0.627 & 13.223 & 76.053 & 3.299 \\
\hline & $4-5.6$ & 57.270 & 0.632 & 14.458 & 74.755 & 2.961 \\
\hline & $5.6-8$ & 58.136 & 0.576 & 13.433 & 76.893 & 3.328 \\
\hline & $8-11.2$ & 57.459 & 0.686 & 12.367 & 78.476 & 3.646 \\
\hline \multirow[t]{4}{*}{ RA3 } & Faury & 56.586 & 0.524 & 6.310 & 87.885 & 8.203 \\
\hline & $4-5.6$ & 54.617 & 0.470 & 8.022 & 85.313 & 5.809 \\
\hline & $5.6-8$ & 57.279 & 0.471 & 6.074 & 89.395 & 8.430 \\
\hline & $8-11.2$ & 59.163 & 0.631 & 5.275 & 91.085 & 10.217 \\
\hline
\end{tabular}

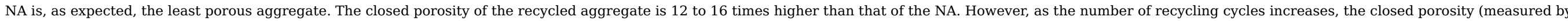

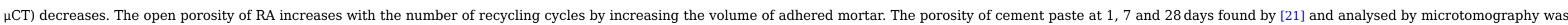

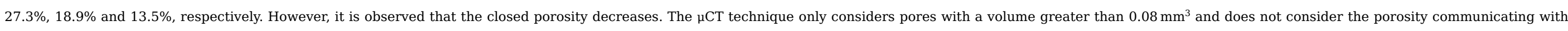
the exterior through capillarity.

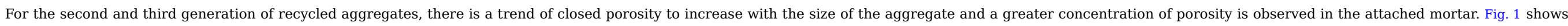

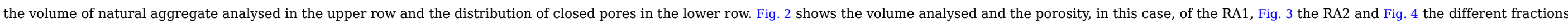
of RA3. 


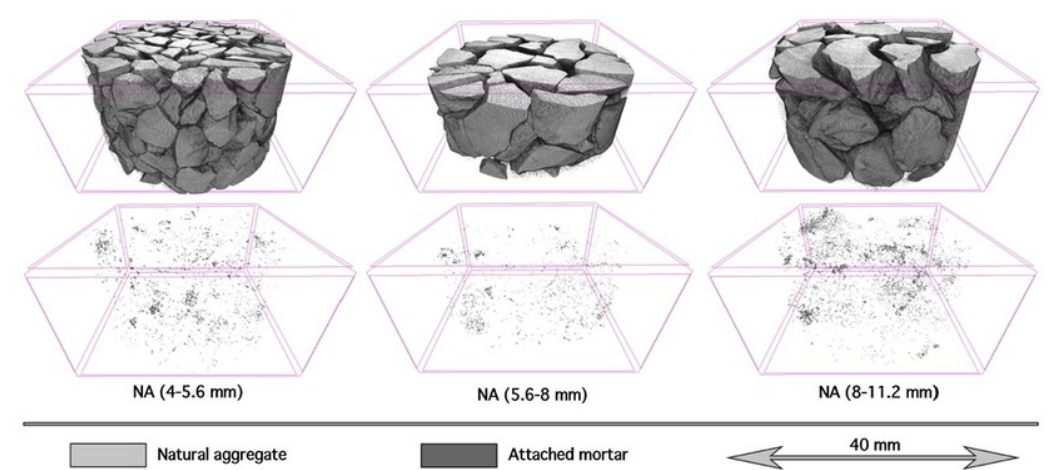

Fig. 1 Analysed volume (upper row) and closed porosity (lower row) of the different fractions of the coarse natural aggregate.

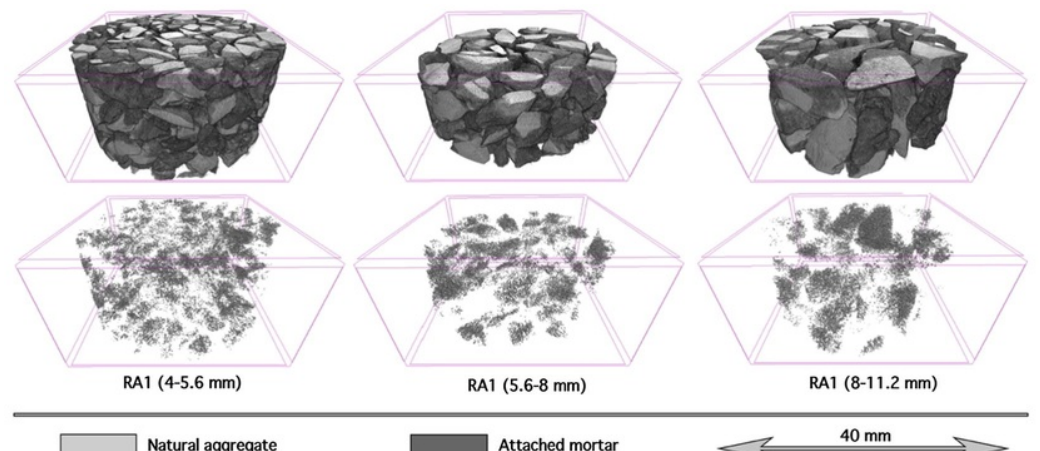

Fig. 2 Analysed volume (upper row) and closed porosity (lower row) of the different fractions of the first-generation recycled aggregate.

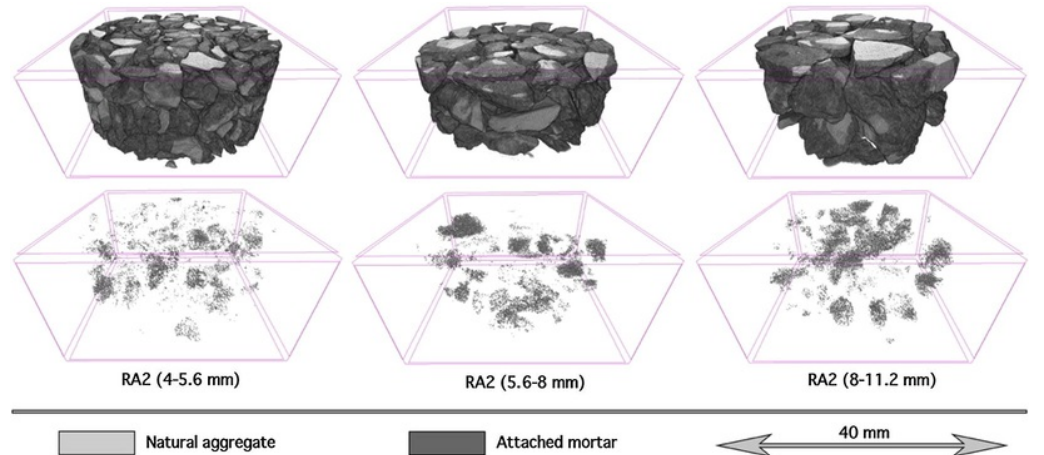

Fig. 3 Analysed volume (upper row) and closed porosity (lower row) of the different fractions of the second-generation recycled aggregate. 


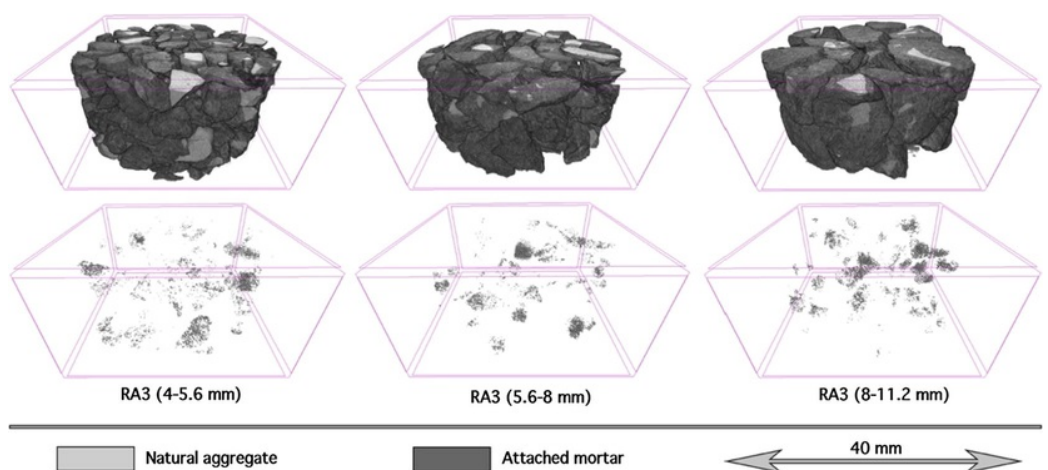

Fig. 4 Analysed volume (upper row) and closed porosity (lower row) of the different fractions of the third-generation recycled aggregate.

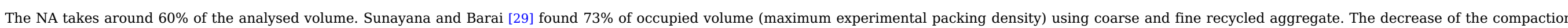

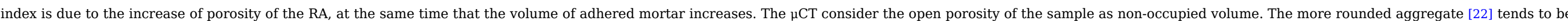
better-packed (decrease of inter-aggregate voids) but the ratio between the volume of the solid fraction and the volume occupied by the aggregate decreases.

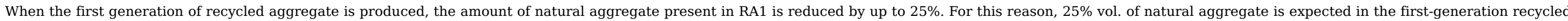

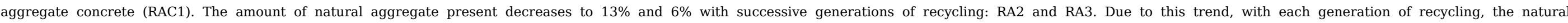
aggregate/adhered mortar ratio decreases and a maximum number of cycles is expected until the presence of coarse natural aggregate is reduced to near zero values.

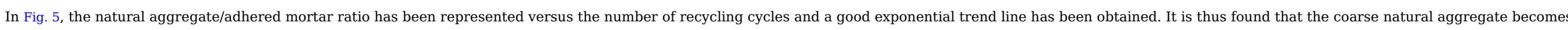
negligible between the fourth and the fifth cycle.

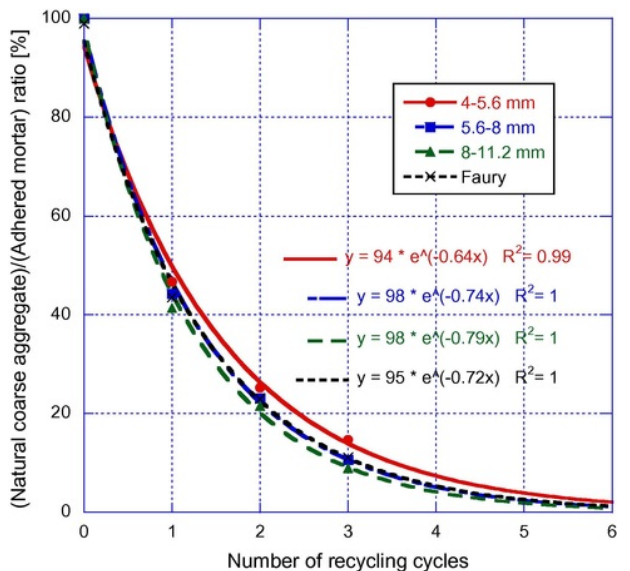

Fig. 5 Natural coarse aggregate and adhered mortar volume ratio of the coarse recycled aggregate versus the number of recycling cycles.

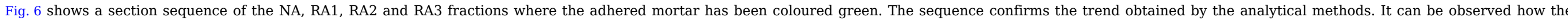

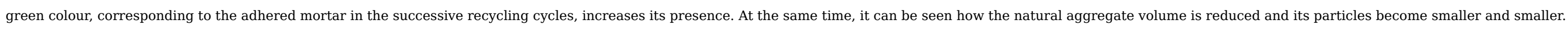




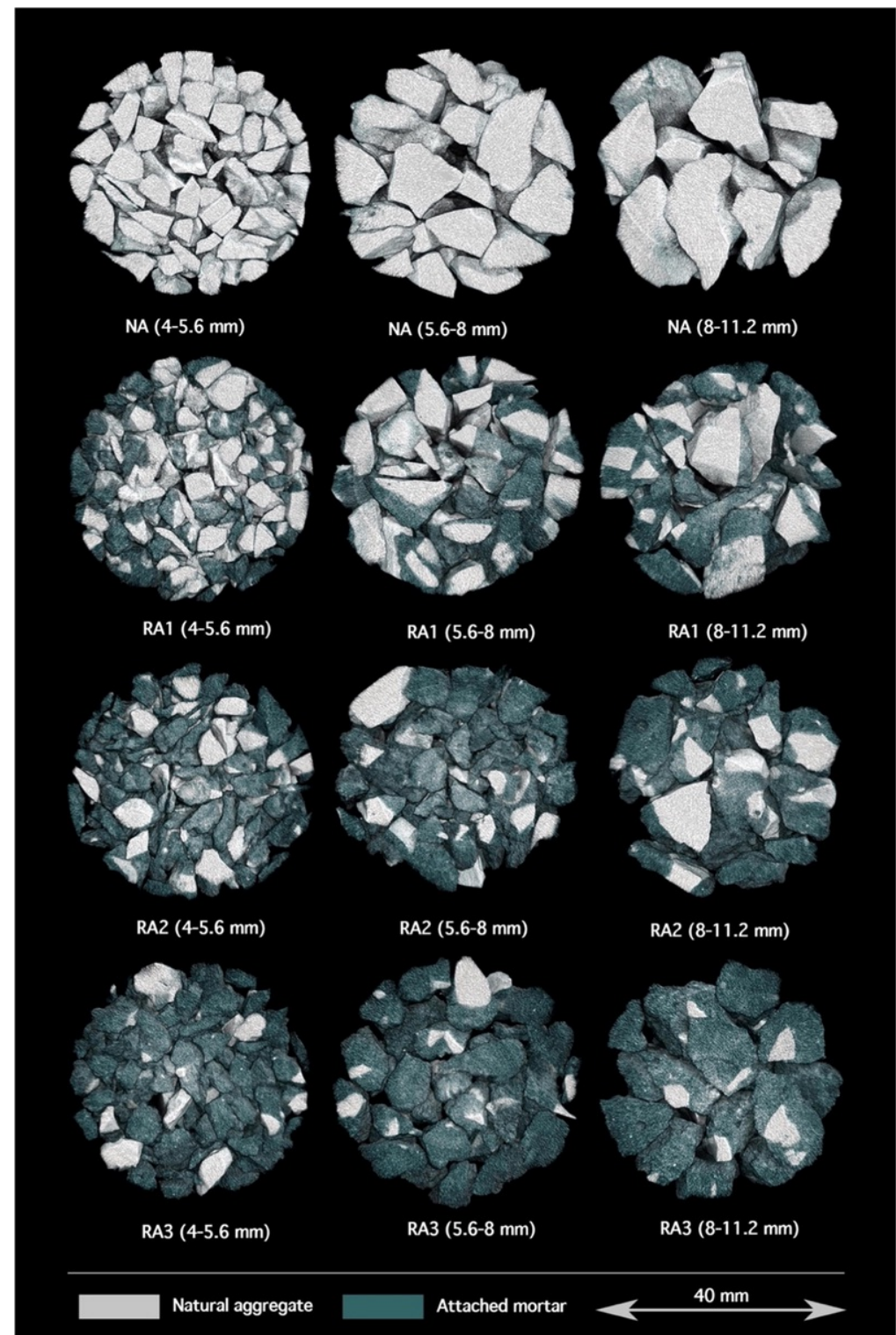

Fig. 6 Analysed section of the natural and recycled coarse aggregate samples where the adhered mortar has been coloured green.

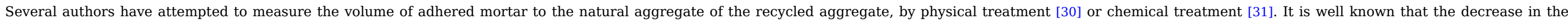
performance of the recycled aggregate is mainly due to the presence of this phase. The technique proposed here allowed easily evaluating the amount of adhered mortar.

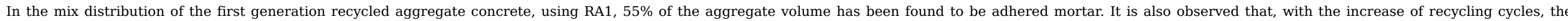

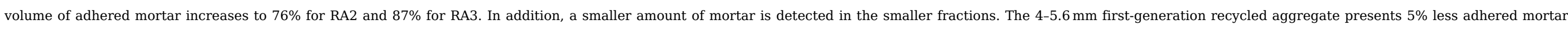

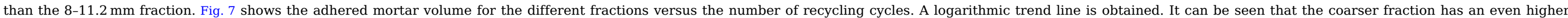




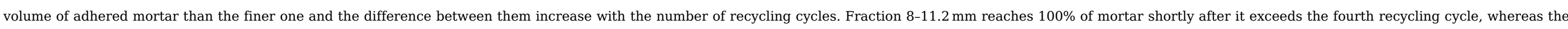

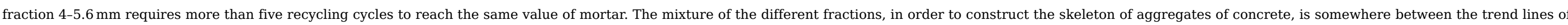
the fractions analysed above and it reaches $100 \%$ of mortar only after between four and five recycling cycles.

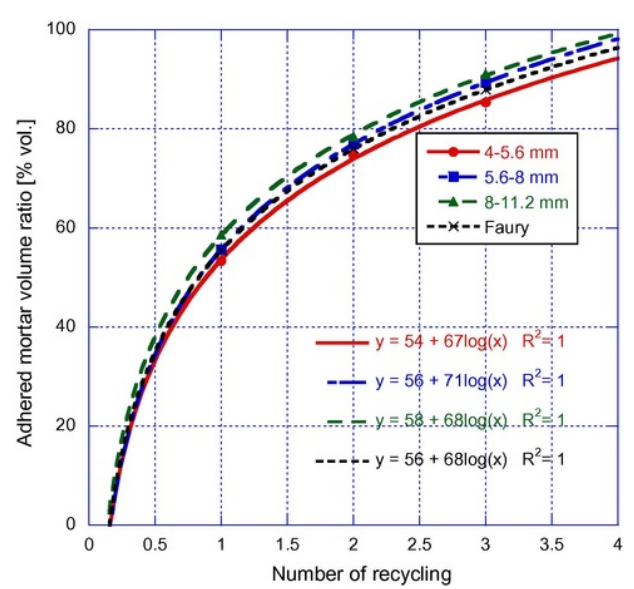

Fig. 7 Adhered mortar volume of the coarse recycled aggregate versus the number of recycling cycles.

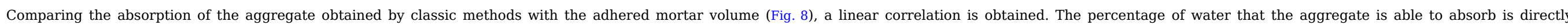

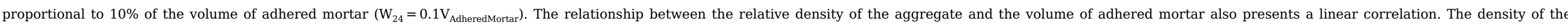
aggregate shows a strong decrease after the first recycling cycle, being the decrease smaller with the second and third cycles, in a similar way to what happens with the volume increase of adhered mortar.

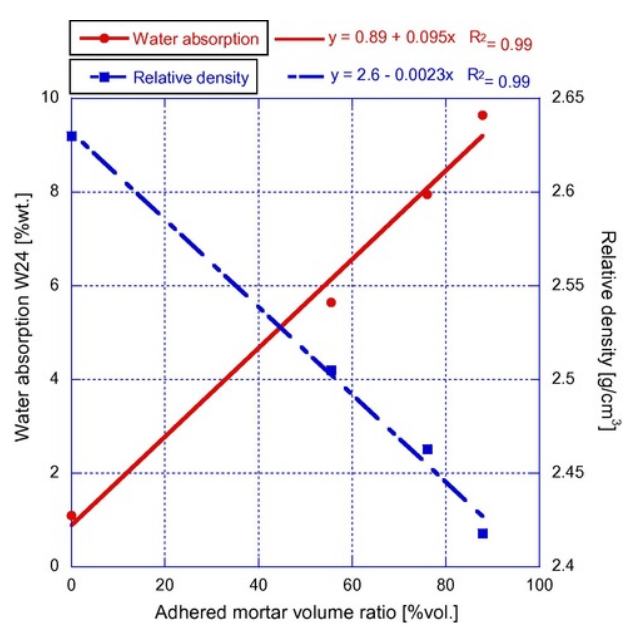

Fig. 8 Water absorption and relative density versus adhered mortar volume of the coarse recycled aggregate.

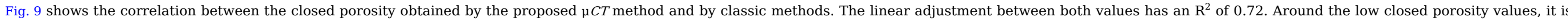

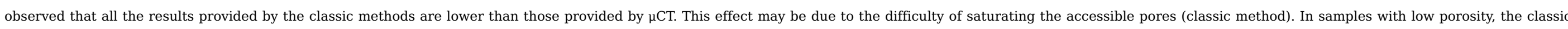

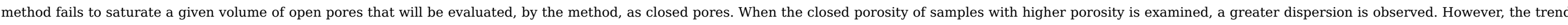

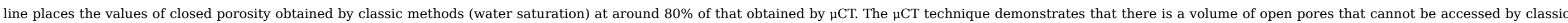




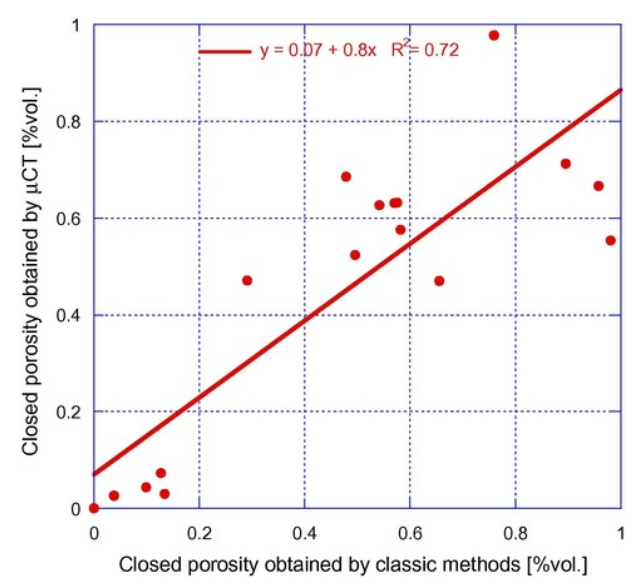

Fig. 9 Closed porosity obtained the proposed method versus classic method.

\subsection{Scan electron microscopy}

Table 5 shows the elemental chemical composition of the control and recycled aggregates.

Table 5 Elemental chemical composition of the recycled aggregates obtained by SEM.

\begin{tabular}{|c|c|c|c|c|c|c|c|c|c|c|c|c|c|c|}
\hline \multirow{2}{*}{$\begin{array}{l}\text { Elem. } \\
\text { Quant. }\end{array}$} & \multicolumn{2}{|c|}{$\mathrm{O}$} & \multicolumn{2}{|c|}{ C } & \multicolumn{2}{|c|}{$\mathrm{Si}$} & \multicolumn{2}{|c|}{$\mathrm{Ca}$} & \multicolumn{2}{|c|}{$\mathrm{Al}$} & \multicolumn{2}{|c|}{ S } & \multicolumn{2}{|c|}{ K } \\
\hline & Atm.\% & wt.\% & Atm.\% & wt.\% & Atm.\% & wt.\% & Atm.\% & wt.\% & Atm.\% & wt.\% & Atm.\% & wt.\% & Atm.\% & wt.\% \\
\hline RA1 & 66.26 & 54.40 & 12.75 & 7.86 & 7.63 & 11.00 & 12.25 & 25.20 & 1.11 & 1.54 & - & - & - & - \\
\hline RA2 & 65.07 & 54.78 & 16.32 & 10.31 & 5.77 & 8.53 & 11.39 & 24.02 & 0.74 & 1.05 & 0.36 & 0.61 & 0.34 & 0.69 \\
\hline RA3 & 62.95 & 54.06 & 19.38 & 12.49 & 6.01 & 9.06 & 10.21 & 21.97 & 0.77 & 1.12 & 0.29 & 0.51 & 0.38 & 0.79 \\
\hline
\end{tabular}

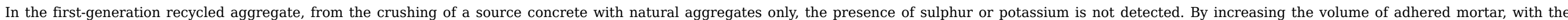

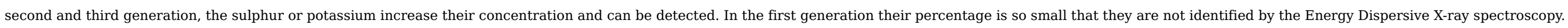

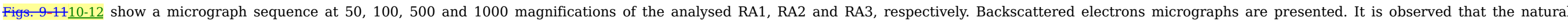

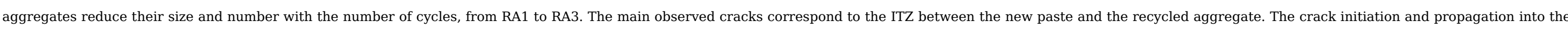

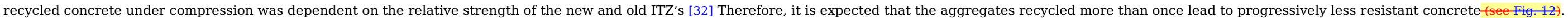




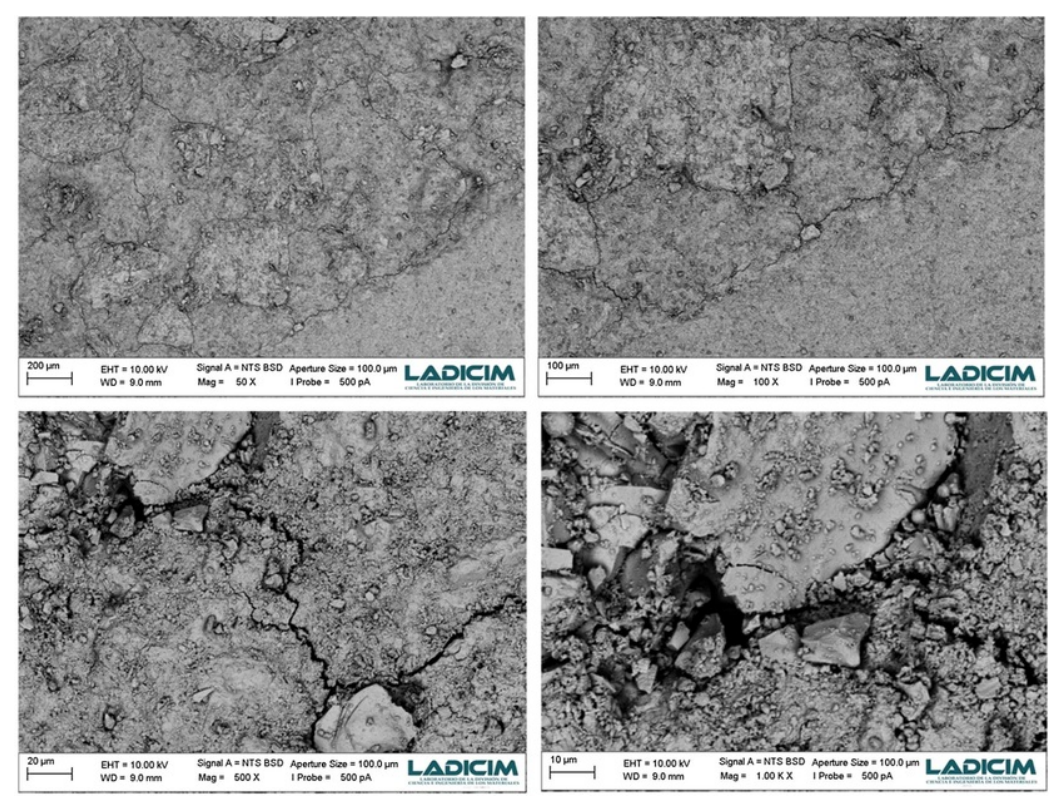

Fig. 10 Scan electron micrograph sequence $(50 x, 100 x, 500 x$ and 1000x) of a region of aggregate-cement paste interphase of RA1
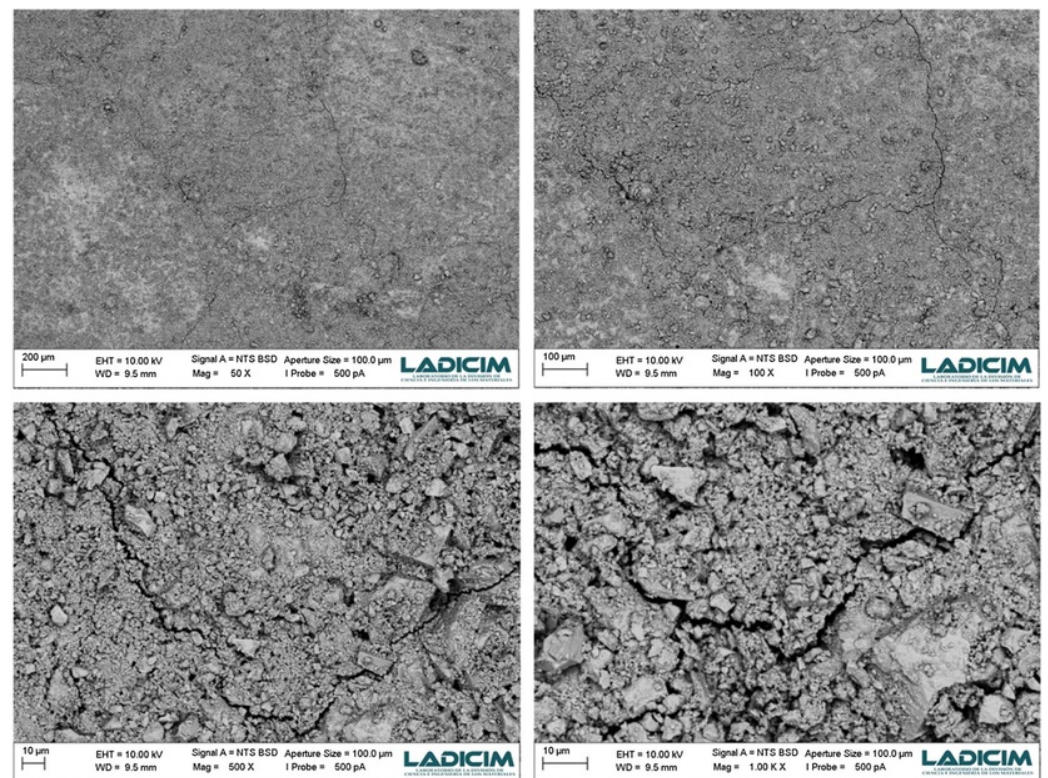

Fig. 11 Scan electron micrograph sequence $(50 \times, 100 \times, 500 \times$ and $1000 \times)$ of a region of aggregate-cement paste interphase of RA2. 

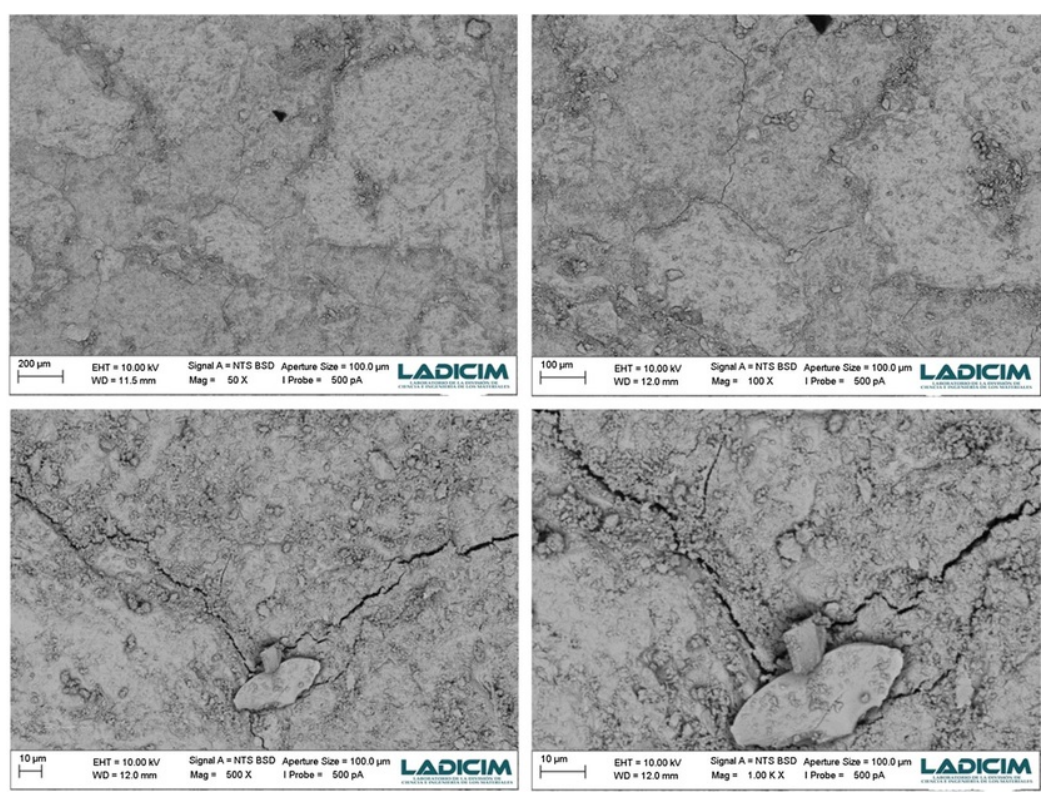

Fig. 12 Scan electron micrograph sequence $(50 x, 100 x, 500 x$ and 1000x) of a region of aggregate-cement paste interphase of RA3.

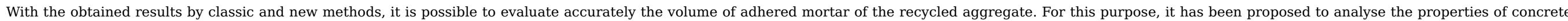

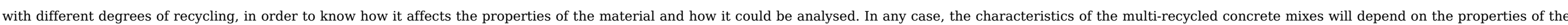
source concrete, the proposed mix proportions and its cement. A sustainable future implies multi-recycled concrete, so the study of new combinations will be a very important future line of research.

\section{Conclusions}

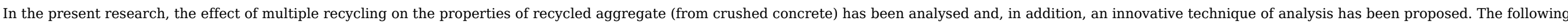
conclusions can be drawn.

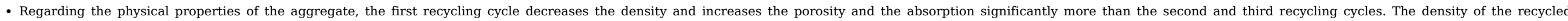
aggregates decreases as larger aggregates are selected and this effect is the more pronounced the more often the aggregates are recycled.

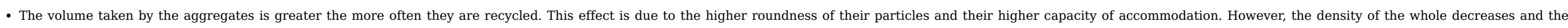
absorption increases because of the higher volume of adhered mortar

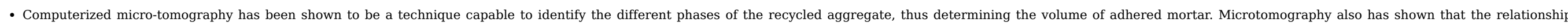
between the volume of natural aggregate and adhered mortar is asymptotically decreasing. It is observed that from the second cycle on this ratio is below $20 \%$.

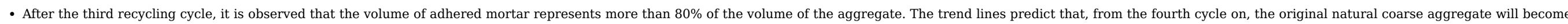
negligible and the recycled aggregate will consist of almost $100 \%$ mortar.

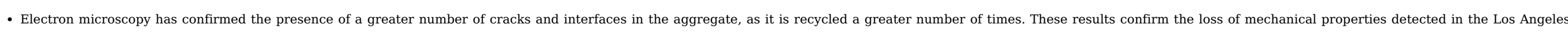
coefficient tests.

\section{Uncited reference}




\section{Acknowledgments}

The authors would like to thank:

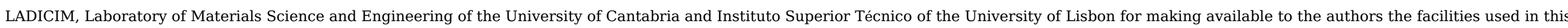
research.

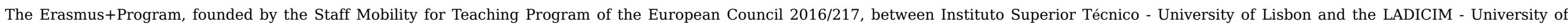
Cantabria.

CERIS and the Foundation for Science and Technology (FCT) for funding this research.

\section{References}

[1] B. González-Fonteboa and F. Martínez-Abella, Shear strength of recycled concrete beams, Constr. Build. Mater. 21, 2007, 887-893.

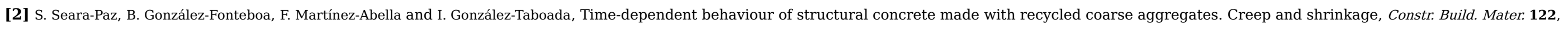
2016, 95-109.

[3] C. Thomas, J. Setién, J.A. Polanco, I. Lombillo and A. Cimentada, Fatigue limit of recycled aggregate concrete, Constr. Build. Mater. 52, 2014, 146-154.

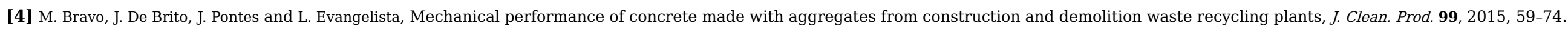

[5] R.V. Silva, J. De Brito and R.K. Dhir, The influence of the use of recycled aggregates on the compressive strength of concrete: a review, Eur. J. Environ. Civil Eng. 19 (7), 2015, 825-849.

[6] D. Pedro, J. De Brito and L. Evangelista, Influence of the use of recycled concrete aggregates from different sources on structural concrete, Constr. Build. Mater. 71, 2014, 141-151.

[7] C. Thomas, J. Setién and J.A. Polanco, Structural recycled aggregate concrete made with precast wastes, Constr. Build. Mater. 114, $2016,536-546$.

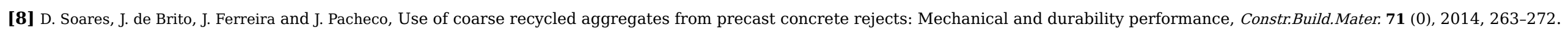

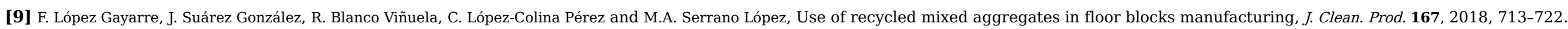

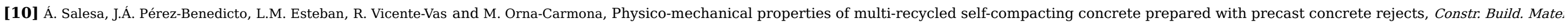
153, 2017, 364-373.

[11] V. Corinaldesi and G. Moriconi, The role of industrial by-products in self-compacting concrete, Constr. Build. Mater. 25 (8), 2011, $3181-3186$.

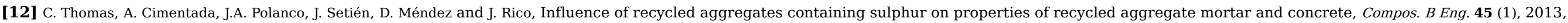
474-485.

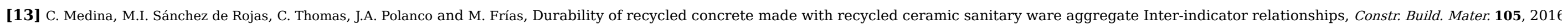
$480-486$.

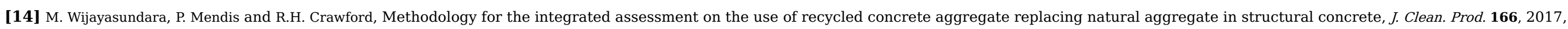
321-334.

[15] C. Thomas, J. Setién, J.A. Polanco, P. Alaejos and M.S. de Juan, Durability of recycled aggregate concrete, Constr. Build. Mater. 40, $2013,1054-1065$.

[16] Valeria Corinaldesi, Structural concrete prepared with coarse recycled concrete aggregate: from investigation to design, Adv. Civil Eng. 2012, 2011, 1-6. 


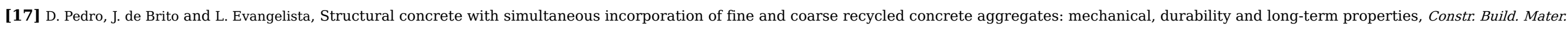
154, 2017, 294-309.

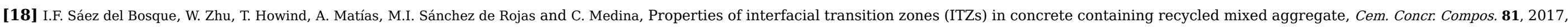
$25-34$.

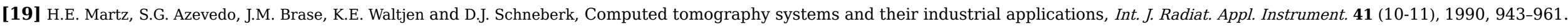

[20] I.L. Morgan, H. Ellinger, R. Klinksiek and J.N. Thomson, Examination of concrete by computerized tomography, J. Am. Concr. Inst. 77 (1), $1980,23-27$.

[21] M. Zhang, Pore-scale modelling of relative permeability of cementitious materials using X-ray computed microtomography images, Cem. Concr. Res. 95, 2017, 18-29.

[22] M.B. Leite and P.J.M. Monteiro, Microstructural analysis of recycled concrete using X-ray microtomography, Cem. Concr. Res. 3 (81), 2016, 38-48.

[23] C. Thomas, I. Sosa, J. Setién, J.A. Polanco and A.I. Cimentada, Evaluation of the fatigue behaviour of recycled aggregate concrete, J. Clean. Prod. 65, 2014, 397-405.

[24] K. Onoue, M. Tokitsu, M. Ohtsu and T.A. Bier, Fatigue characteristics of steel-making slag concrete under compression in submerged condition, Constr.Build.Mater. 70 (0), 2014, 231-242.

[25] J. Xiao, H. Li and Z. Yang, Fatigue behavior of recycled aggregate concrete under compression and bending cyclic loadings, Constr. Build. Mater. 38 (0), 2013, 681-688.

[26] C.J. Zega, G.S. Coelho, Y.A. Dos Santos, A.A Di Villagrán-Zaccardi and Maio, Performance of recycled concretes exposed to sulphate soil for 10 years, Constr. Build. Mater. 102, 2016, 714-721.

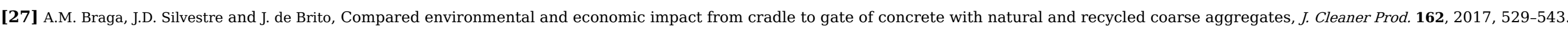

[28] P. Niewiadomski, D. Stefaniuk and J. Hoła, Microstructural analysis of self-compacting concrete modified with the addition of nanoparticles, Proc. Eng. 172, 2017, 776-783.

[29] S. Sunayana and S.V. Barai, Recycled aggregate concrete incorporating fly ash: comparative study on particle packing and conventional method, Constr. Build. Mater. 156, 2017, 376-386.

[30] V.W.Y. Tam, C.M. Tam and K.N. Le, Removal of cement mortar remains from recycled aggregate using pre-soaking approaches, Resour. Conserv. Recycl. 50 (1), 2007 , 82-101.

[31] H. Tateyashiki, H. Shima, Y. Matsumoto and Y. Koga, Properties of concrete with high quality recycled aggregate by heat and rubbing method, Proc. JCI 23 (2), 2001, 61-66.

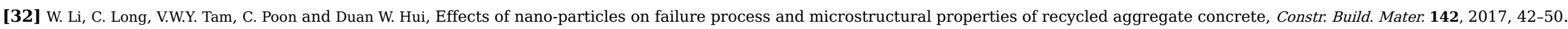

\section{Highlights}

- Multiple recycling properties of recycled aggregate has been analysed.

- Computerized micro-tomography identifies phases of the recycled aggregate.

- After 3 recycling the volume of adhered mortar is $80 \%$ of the aggregate.

- Density decreases with recycling cycles and the size of the aggregate.

\section{Oueries and Answers}

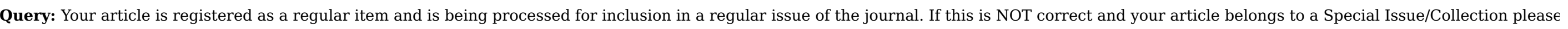
contact t.gunasekaran.1@elsevier.com immediately prior to returning your corrections.

Answer: Yes 
Query: The author names have been tagged as given names and surnames (surnames are highlighted in teal color). Please confirm if they have been identified correctly.

Answer: They are correct identify but Sainz-Aja was wrong written. Also in the sent manuscript, sorry.

Query: Please note that Fig. 12 are not cited in the text. Please check that the citations suggested by the copyeditor are in the appropriate place, and correct if necessary. Answer: There was a mistake at the beginning of the paragraph: Fig. 9-11 was changed by Fig. 10-12.

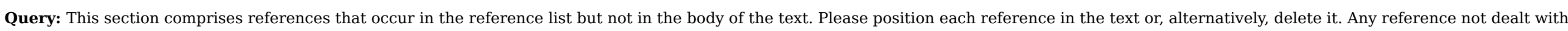
will be retained in this section.

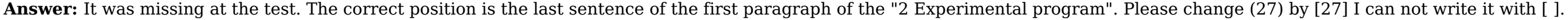

Query: Please check the edit(s) made in Table 5, and correct if necessary.

Answer: The table header was corrected. 